\title{
Is Aspartate an Excitatory Neurotransmitter?
}

\author{
Bruce E. Herring, ${ }^{1 *}$ Katlin Silm, ${ }^{2,3 *}$ Robert H. Edwards, ${ }^{2,3}$ and Roger A. Nicoll ${ }^{1,2}$ \\ ${ }^{1}$ Department of Cellular and Molecular Pharmacology, ${ }^{2}$ Department of Physiology, and ${ }^{3}$ Department of Neurology, University of California, San Francisco, \\ San Francisco, California 94158
}

Recent evidence has resurrected the idea that the amino acid aspartate, a selective NMDA receptor agonist, is a neurotransmitter. Using a mouse that lacks the glutamate-selective vesicular transporter VGLUT1, we find that glutamate alone fully accounts for the activation of NMDA receptors at excitatory synapses in the hippocampus. This excludes a role for aspartate and, by extension, a recently proposed role for the sialic acid transporter sialin in excitatory transmission.

Key words: aspartate; glutamate; neurotransmitter; sialin; VGLUT1

\section{Significance Statement}

It has been proposed that the amino acid aspartate serves as a neurotransmitter. Although aspartate is a selective agonist for NMDA receptors, we find that glutamate alone fully accounts for neurotransmission at excitatory synapses in the hippocampus, excluding a role for aspartate.

\section{Introduction}

The traditional view of neurotransmission is that one neuron releases just a single type of classical transmitter such as acetylcholine, glutamate, GABA, and the monoamines. The discovery of neuropeptides and their release from the same terminals that release classical transmitters increased the versatility of neurotransmission (Hökfelt et al., 2000). It has also been found that multiple classical transmitters can be stored and released from the same vesicle (Jonas et al., 1998). For example, the vesicular GABA transporter VGAT packages glycine as well as GABA (Wojcik et al., 2006) and vesicular content reflects the cytosolic concentration of amino acid in the terminal. The presynaptic level of amino acid in turn depends on expression of glutamic acid decarboxylase, the biosynthetic enzyme for GABA, and/or the glycine transporter GLYT2 (Nicoll and Malenka, 1998). In the case of other classical transmitters released from the same neuron, such as dopamine and glutamate, serotonin and glutamate, and acetylcholine and glutamate, recent evidence has suggested costorage in the same vesicles, but it remains unclear whether this is

Received Feb. 6, 2015; revised May 22, 2015; accepted June 2, 2015.

Author contributions: B.E.H., K.S., R.H.E., and R.A.N. designed research; B.E.H. and K.S. performed research; B.E.H. and K.S. analyzed data; B.E.H., R.H.E., and R.A.N. wrote the paper.

This work was supported by the National Institute of Mental Health-National Institutes of Health (R.A.N., R.H.E., and B.E.H.) and the National Institute on Drug Abuse (R.H.E.). K.S. was supported by a fellowship from the Fondation Fyssen.

The authors declare no competing financial interests.

*B.E.H. and K.S. contributed equally to this work.

Correspondence should be addressed to either Roger A. Nicoll or Robert H. Edwards, Department of Cellular and Molecular Pharmacology, University of California, $60016^{\text {th }}$ Street, Mission Bay Campus, San Francisco, CA 94158; E-mail: roger.nicoll@ucsf.edu or Robert.Edwards@ucsf.edu.

DOI:10.1523/JNEUROSCI.0524-15.2015

Copyright $\odot 2015$ the authors $\quad$ 0270-6474/15/3510168-04\$15.00/0 always the case (Gras et al., 2008; Hnasko et al., 2010; Hnasko and Edwards, 2012; Tritsch et al., 2012; Nelson et al., 2014).

One of the oldest debates about co-transmission involves glutamate and the closely related aspartate. Both of these excitatory amino acids satisfy many of the criteria required for the role of neurotransmitter. Present in the brain, they are both taken up into nerve terminals and released upon depolarization (Morland et al., 2013). Although previous work has established a role for glutamate as the transmitter at most excitatory synapses in the brain, the role of aspartate has remained unclear (Fleck et al., 1993; Yuzaki et al., 1996; Gundersen et al., 1998; Dingledine et al., 1999). Two properties of aspartate make it of particular interest. First, in contrast to other vesicular neurotransmitter transporters that recognize multiple substrates, the vesicular glutamate transporters VGLUT1-3 do not transport or even recognize aspartate (Reimer and Edwards, 2004). Therefore, if aspartate serves as a transmitter, then another transporter must be involved. Second, aspartate is a highly selective agonist for NMDAR-type glutamate receptors and does not activate AMPA-type glutamate receptors (Patneau and Mayer, 1990). Synapses releasing only aspartate should therefore generate only NMDAR currents despite a full postsynaptic complement of AMPARs. In this case, variation in the vesicular content of glutamate and aspartate should have a profound effect on the relative contribution of AMPARs and NMDARs to synaptic transmission.

Recent work has suggested that sialin, a sialic acid transporter closely related in sequence to the VGLUTs, can also transport both glutamate and aspartate (Miyaji et al., 2008; Miyaji et al., 2011). Further, it has been proposed that sialin localizes to synaptic vesicles. These observations predict that, in the absence of 
A

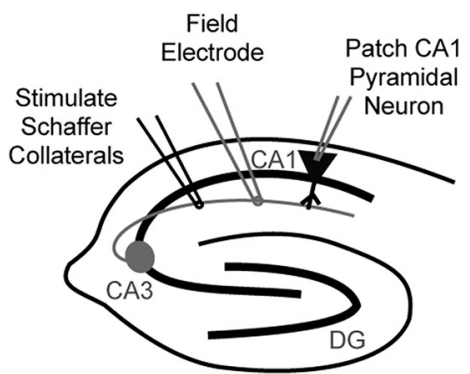

B

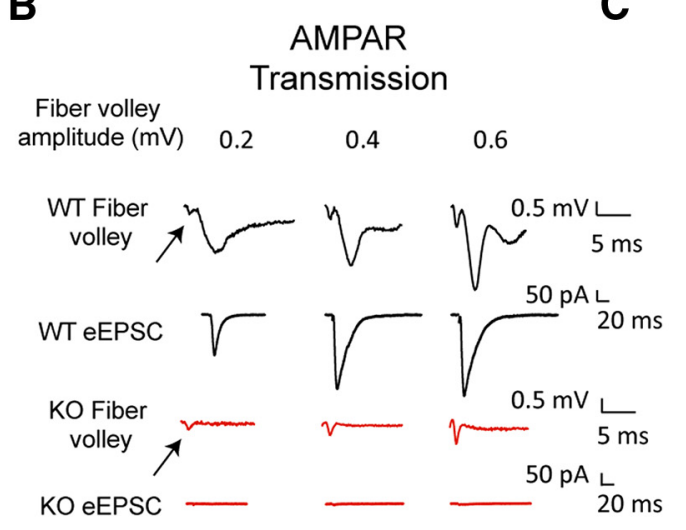

AMPAR-eEPSC summary

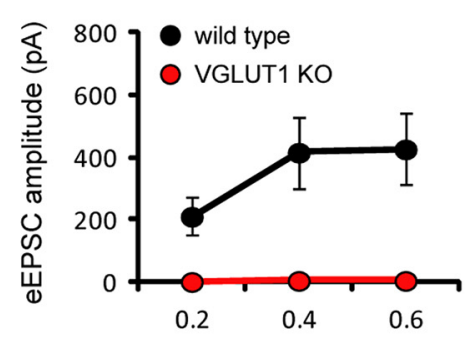

Fiber volley amplitude $(\mathrm{mV})$
D

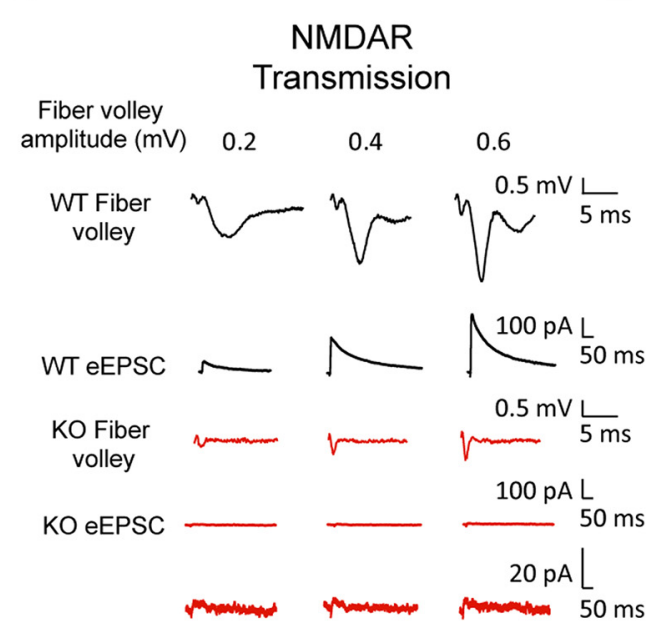

\section{NMDAR-eEPSC summary}

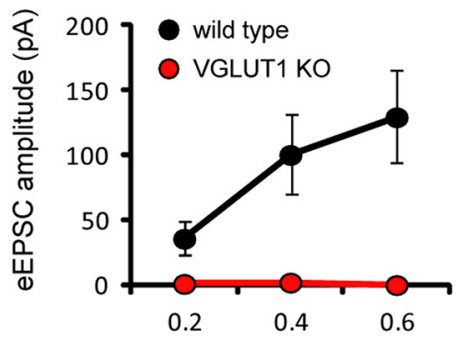

Fiber volley amplitude $(\mathrm{mV})$

Figure 1. NMDAR-eEPSC amplitude is severely reduced in VGLUT1 KO mice. $A$, Concurrent recordings of fiber volleys (Field Electrode) and AMPAR- and NMDAR-eEPSCs (Patch CA1 Pyramidal Neuron) in acute hippocampal slices from wild type and VGLUT1 KO mice. $\boldsymbol{B}$, Representative AMPAR-eEPSC traces from wild type (black) and VGLUT1 KO mice (red) at three fiber volley amplitudes. Arrows point to fiber volleys. C, Average AMPAR-eEPSC amplitudes (mean \pm SEM) from wild type (black) and VGLUT1 KO mice (red) at three fiber volley amplitudes (wild type, $n=7$ neurons; VGLUT1 KO, $n=5$ neurons). D, Sample NMDAR-eEPSC traces from wild type (black) and VGLUT1 KO mice (red) at three fiber volley amplitudes. Vertically expanded eEPSCs are shown for the VGLUT1 KO. $E$, Average NMDAR-eEPSC amplitudes (mean \pm SEM) from wild type (black) and VGLUT1 KO mice (red) at three fiber volley amplitudes (wild type, $n=7$ neurons; VGLUT1 K0, $n=5$ neurons).

VGLUTs, excitatory synapses should signal using synaptic vesicles with a higher aspartate/glutamate ratio and thus increase the contribution of NMDARs to synaptic transmission relative to synaptic AMPARs. Previous work has shown that mature hippocampal synapses without VGLUT1 exhibit severely reduced AMPAR responses (Fremeau et al., 2004). However, the strength of NMDAR responses at VGLUT1 lacking synapses has not been examined. We now find that, in the absence of VGLUT1, there is no preferential activation of NMDARs. This result shows that, regardless of mechanism (Miyaji et al., 2008; Morland et al., 2013), any aspartate released from synaptic vesicles is at a concentration too low to be physiologically relevant.

\section{Materials and Methods}

Animal care and husbandry. VGLUT1 knockout $(\mathrm{KO})$ and wild type littermate mice were housed with $12 \mathrm{~h}$ light/dark cycle and unlimited food and water. From postnatal day 15 (P15), all mice received Nutra-Gel Diet (BioServ) food supplement. After weaning, VGLUT1 KO mice were separated from littermates and fed daily with Nutra-Gel to promote their survival. Both male and female mice were used and all experiments were conducted in accordance with University of California San Francisco Institutional Animal Care and Use Committee.

RT-PCR. Region CA3 was dissected from 6- to 9-week-old wild type or VGLUT1 KO mice. Total RNA was extracted using TRIzol (Invitrogen) and cDNA synthesized from $600 \mathrm{ng}$ of RNA using the Superscript III Fist Strand Synthesis SuperMix for qRT-PCR (Life Technologies) according to the manufacturer's guidelines. Real-time quantitative PCR was performed using SYBR GreenER qPCR SuperMix (Invitrogen). The following oligonucleotide primers were used for both RT-PCR and quantitative PCR: 5'-GTAT GCTGGCATCCTCTTGG-3' and 5'-GAT ACAGAAGACAGTCTGCC-3' amplifying nucleotides 1321-1441 in sialin cDNA spanning the junction of exons 10 and 11 (Prolo et al., 2009); and 5'-GTATGCTGGCATC CTCTTGG- $3^{\prime}$ and $5^{\prime}$-CCCATTCCCACC ATCACACCCTGGT- $3^{\prime}$ amplifying $\beta$-actin cDNA region spanning nucleotides $121-252$ (exons 2 and 3 ).

Electrophysiology. Voltage-clamp recordings from CA1 pyramidal neurons and field recordings were taken from acute hippocampal slices from P67-P85 mice. Then, $300 \mu \mathrm{m}$ transverse hippocampal slices were cut using a Microslicer DTK-Zerol (Ted Pella) in chilled high sucrose cutting solution containing the following (in mM): $2.5 \mathrm{KCl}, 7 \mathrm{MgSO}_{4}, 1.25 \mathrm{NaH}_{2} \mathrm{PO}_{4}, 25$ $\mathrm{NaHCO}_{3}, 7$ glucose, 210 sucrose, 1.3 ascorbic acid, and 3 sodium pyruvate. The slices were then incubated for $1 \mathrm{~h}$ at $34^{\circ} \mathrm{C}$ in artificial CSF (aCSF) containing the following (in $\mathrm{mM}$ ): $119 \mathrm{NaCl}, 2.5$ $\mathrm{KCl}, 1 \mathrm{NaH}_{2} \mathrm{PO}_{4}, 26.2 \mathrm{NaHCO}_{3}, 11$ glucose, 2.5 $\mathrm{mM} \mathrm{CaCl}_{2}$, and $1.3 \mathrm{~mm} \mathrm{MgSO}_{4}$. The aCSF was bubbled with $95 \% \mathrm{O}_{2}$ and $5 \% \mathrm{CO}_{2}$ to maintain $\mathrm{pH}$ and the slices were allowed to recover at room temperature for $45 \mathrm{~min}$ to $1 \mathrm{~h}$ before recording at room temperature. While recording, slices were transferred to a perfusion stage on an Olympus BX50WI upright microscope and perfused at $2.5 \mathrm{ml} \mathrm{min}^{-1}$ with aCSF containing $0.1 \mathrm{~mm}$ picrotoxin. Where indicated, aCSF containing $30 \mu \mathrm{M}$ glycine was applied for several minutes before measuring AMPAR- and NMDAR-mediated currents. Synaptic responses were evoked by stimulating with a monopolar glass electrode filled with aCSF in stratum radiatum of CA1. To ensure stable voltage-clamp recording, membrane holding current, input resistance, and pipette series resistance were monitored throughout recording. Cells were discarded if holding currents were larger than $200 \mathrm{pA}$, series resistance varied by $25 \%$ or 
more during a recording session, or series resistance exceeded $30 \mathrm{M} \Omega$. Data were gathered through a MultiClamp 700B amplifier (Molecular Devices), filtered at $2 \mathrm{kHz}$, and digitized at 10 $\mathrm{kHz}$.

Simultaneous whole-cell synaptic and field recordings. Simultaneous whole-cell voltageclamp and field recordings were performed by placing a field electrode in stratum radiatum of CA1 between the stimulating electrode and the whole-cell voltage-clamped CA1 pyramidal neuron. The field electrode was filled with aCSF. For whole-cell voltage-clamp recordings, the internal recording solution contained the following (in mM): $135 \mathrm{CsMeSO}_{4}, 8 \mathrm{NaCl}$, 10 HEPES, 0.3 EGTA, 5 QX-314, 4 Mg-ATP, and $0.3 \mathrm{Na}$-GTP. Osmolarity was adjusted to 290-295 mOsm and pH buffered at 7.3-7.4. AMPAR-mediated responses were isolated by voltage clamping the cell at $-70 \mathrm{mV}$, whereas NMDAR responses were recorded at $+40 \mathrm{mV}$ with amplitudes taken $100 \mathrm{~ms}$ after stimulation to avoid contamination by AMPAR current.

Statistics. Mann-Whitney U tests, MannWhitney Rank sign tests, and one sample $t$ tests were used to determine statistical significance between groups where indicated. Data analysis was performed in Igor Pro (Wavemetrics), KaleidaGraph (Synergy Software), Excel (Microsoft), and Prism 6 (GraphPad).

\section{Results}

Previous studies have shown that deletion of the glutamate transporter VGLUT1 in CA1 hippocampal pyramidal cells greatly impairs excitatory synaptic transmission (Fremeau et al., 2004). Modest at first due to the transient expression of VGLUT2 early in life, the inhibition becomes essentially complete several weeks after birth. We have therefore used VGLUT1 KO mice at least 2 months old, when AMPARmediated field potentials have disappeared. To ensure that the stimulating electrode adequately activated presynaptic axons, we monitored the size of the fiber volley with a field potential electrode placed in stratum radiatum (Fig. $1 A, B$, arrows). In wild type slices, the fiber volley was associated with large AMPAR-mediated field EPSPs (fEPSPs) and large evoked EPSCs (eEPSCs) simultaneously recorded at $-70 \mathrm{mV}$ (Fig. $1 B$, black traces). In the KO, however, both fEPSPs and eEPSCs were virtually absent (Fig. $1 B$, red traces). Figure $1 C$ shows the absence of eEPSCs in $\mathrm{KO}$ mice at three different fiber volley amplitudes (wild type, $n=7$ neurons; VGLUT1 KO, $n=5$ neurons), consistent with previous results (Fremeau et al., 2004). The stimulation was then repeated in the same cells while holding the cells at $+40 \mathrm{mV}$ to enable detection of NMDAR-mediated eEPSCs (Fig. 1D). In wild type slices, a large NMDAR-eEPSC was recorded (Fig. 1D, black traces). However, no eEPSC was detected in the KO slices (red traces). Figure $1 E$ summarizes these results, showing the absence of NMDAR-eEPSCs in KO slices (wild type, $n=7$ neurons; VGLUT1 KO, $n=5$ neurons). The data are consistent with the traditional view that glutamate fully accounts for the synaptic response. If aspartate were also released, an NMDAR-eEPSC should have been observed in the KO.
B

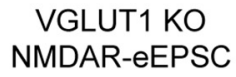

C

\section{AMPAR/NMDAR \\ -eEPSC ratio}

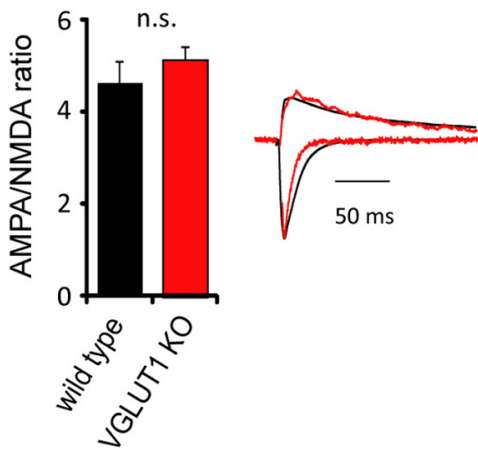

E

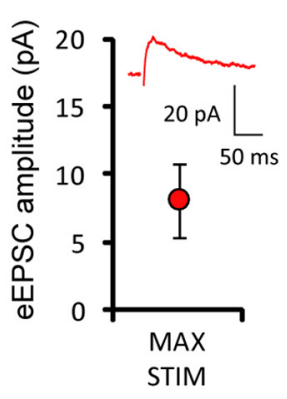

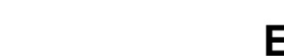

Figure 2. AMPAR/NMDAR-eEPSC amplitude ratios are unchanged in VGLUT1 KO mice. $A$, Average AMPAR-eEPSC amplitude (mean \pm SEM) with maximal Schaffer collateral stimulation in VGLUT1 KO mice ( $n=6$ neurons). Inset shows sample AMPAReEPSC trace. $\boldsymbol{B}$, Average NMDAR-eEPSC amplitude (mean \pm SEM) with maximal Schaffer collateral stimulation in VGLUT1 KO mice Average AMPAR/NMDAR - eEPSC amplitude ratio (mean \pm SEM) for VGLUT1 KO mice before (red) and after (blue) treatment with
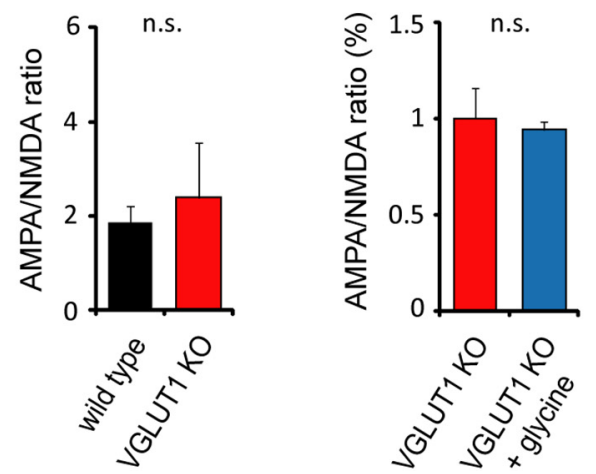

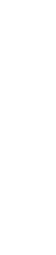

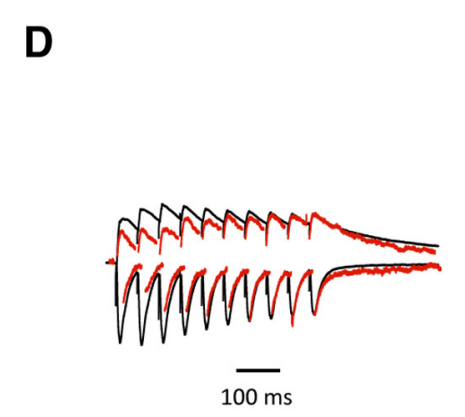

itude
PAR-
mice
EPSC
(red)
Eor
and
with

It is possible that the experiments of Figure 1 were not sensitive enough to detect a small contribution of aspartate to the NMDAR-eEPSC. We therefore increased the stimulus strength to record small AMPAR (Fig. 2A) and NMDAR-eEPSCs (Fig. 2B) from VGLUT1 KO neurons. We then calculated the AMPAR/ NMDAR-eEPSC amplitude ratio and found no difference between cells from wild type and KO mice (wild type, $n=7$ neurons; VGLUT1 KO, $n=6$ neurons, Mann-Whitney $U$ test, $p=0.35$; Fig. $2 C$ ). Because a role for aspartate release might only emerge with strong stimulation, we also examined the response to 10 stimuli given to Schaffer collaterals at $20 \mathrm{~Hz}$. However, the AMPAR/NMDAR ratio of VGLUT1 KO neurons does not differ from wild type neurons under these circumstances (wild type, $n=4$ neurons; VGLUT1 KO, $n=4$ neurons, Mann-Whitney $U$ test, $p=0.48$; Fig. $2 D$ ). To ensure that any increase in the NMDA response was detectable, we also measured AMPAR/NMDAR ratios in VGLUT1 KO neurons before and after application of the NMDAR activator glycine for several minutes and found no change in the response (wild type, $n=3$ neurons; VGLUT1 KO, $n=3$ neurons, Mann-Whitney rank-sign test, $p=0.75$; Fig. $2 E$ ). 

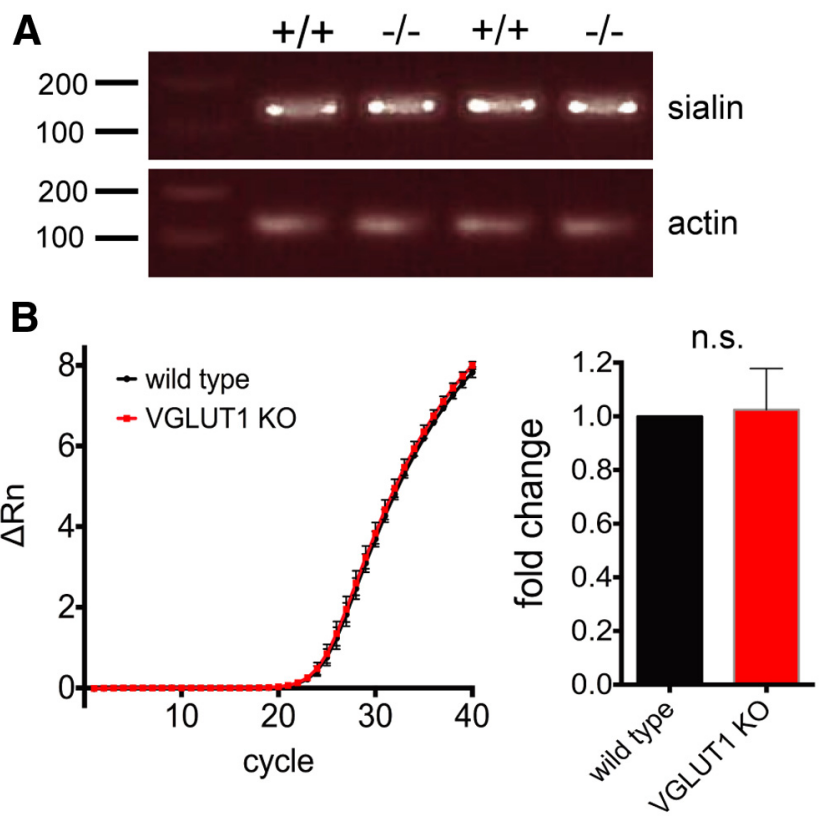

Figure 3. Loss of VGLUT1 does not affect sialin expression in hippocampal region CA3.A, Amplification by RT-PCR shows the expression of sialin (and $\beta$-actin control) mRNA in CA3 of both wild type $(+/+)$ and VGLUT1 $K O(-/-)$ animals. $B$, Quantitative PCR shows no effect of the VGLUT1 $\mathrm{KO}$ on sialin expression. Data are presented as sialin amplification curves and as the fold change of sialin expression in VGLUT1 KO relative to wild type (mean $\pm \mathrm{SEM}, n=3$ animals).

Therefore, NMDA receptors in this preparation appear saturated by glycine, indicating the maximum potential to detect an aspartate-mediated change in the AMPAR/NMDAR ratio with the loss of VGLUT1. We also found that sialin is indeed expressed by cells in CA3 (Fig. 3) and that sialin levels do not change with the loss of VGLUT1 ( $n=3$ animals, one-sample $t$ test, $p=0.803$; Fig. 3). The sample analyzed contains glia and inhibitory neurons as well as pyramidal cells forming synapses in CA1, but the abundance of mRNA in pyramidal cells suggests that they had not changed expression of sialin. Although sialin is expressed in CA3, our results thus exclude the possibility that aspartate contributes to the NMDAR-EPSC.

\section{Discussion}

Our results indicate that aspartate does not contribute to excitatory synaptic transmission in CA1 pyramidal neurons. These results are not consistent with previous work (Miyaji et al., 2008; Miyaji et al., 2011) showing that sialin can transport aspartate as well as glutamate. In fact, the results exclude a mechanism for the accumulation of aspartate into synaptic vesicles dependently or independently of sialin. We do not address the ability of sialin to recognize and transport aspartate and glutamate and it remains possible that synaptic vesicles do contain aspartate. However, the concentration of aspartate released cannot exceed the minimum required to activate NMDARs. Therefore, glutamate transported by VGLUT1 completely accounts for excitatory synaptic transmission in adult CA1 pyramidal cells.

\section{References}

Dingledine R, Borges K, Bowie D, Traynelis SF (1999) The glutamate receptor ion channels. Pharm Rev 51:7-61. Medline

Fleck MW, Henze DA, Barrionuevo G, Palmer AM (1993) Aspartate and glutamate mediate excitatory synaptic transmission in area CA1 of the hippocampus. J Neurosci 13:3944-3955. Medline

Fremeau RT Jr, Kam K, Qureshi T, Johnson J, Copenhagen DR, StormMathisen J, Chaudhry FA, Nicoll RA, Edwards RH (2004) Vesicular glutamate transporters 1 and 2 target to functionally distinct synaptic release sites. Science 304:1815-1819. CrossRef Medline

Gras C, Amilhon B, Lepicard EM, Poirel O, Vinatier J, Herbin M, Dumas S, Tzavara ET, Wade MR, Nomikos GG, Hanoun N, Saurini F, Kemel ML, Gasnier B, Giros B, El Mestikawy S (2008) The vesicular glutamate transporter VGLUT3 synergizes striatal acetylcholine tone. Nat Neurosci 11:292-300. CrossRef Medline

Gundersen V, Chaudhry FA, Bjaalie JG, Fonnum F, Ottersen OP, StormMathisen J (1998) Synaptic vesicular localization and exocytosis of L-aspartate in excitatory nerve terminals: a quantitative immunogold analysis in rat hippocampus. J Neurosci 18:6059-6070. Medline

Hnasko TS, Edwards RH (2012) Neurotransmitter corelease: mechanism and physiological role. Annu Rev Physiol 74:225-243. CrossRef Medline

Hnasko TS, Chuhma N, Zhang H, Goh GY, Sulzer D, Palmiter RD, Rayport S, Edwards RH (2010) Vesicular glutamate transport promotes dopamine storage and glutamate corelease in vivo. Neuron 65:643-656. CrossRef Medline

Hökfelt T, Broberger C, Xu ZQ, Sergeyev V, Ubink R, Diez M (2000) Neuropeptides-an overview. Neuropharmacology 39:1337-1356. CrossRef Medline

Jonas P, Bischofberger J, Sandkühler J (1998) Corelease of two fast neurotransmitters at a central synapse. Science 281:419-424. CrossRef Medline

Miyaji T, Echigo N, Hiasa M, Senoh S, Omote H, Moriyama Y (2008) Identification of a vesicular aspartate transporter. Proc Natl Acad Sci U S A 105:11720-11724. CrossRef Medline

Miyaji T, Omote H, Moriyama Y (2011) Functional characterization of vesicular excitatory amino acid transport by human sialin. J Neurochem 119:1-5. CrossRef Medline

Morland C, Nordengen K, Larsson M, Prolo LM, Farzampour Z, Reimer RJ, Gundersen V (2013) Vesicular uptake and exocytosis of L-aspartate is independent of sialin. FASEB J 27:1264-1274. Medline

Nelson AB, Hammack N, Yang CF, Shah NM, Seal RP, Kreitzer AC (2014) Striatal cholinergic interneurons Drive GABA release from dopamine terminals. Neuron 82:63-70. CrossRef Medline

Nicoll RA, Malenka RC (1998) A tale of two transmitters. Science 281:360 361. CrossRef Medline

Patneau DK, Mayer ML (1990) Structure-activity relationships for amino acid transmitter candidates acting at N-methyl-D-aspartate and quisqualate receptors. J Neurosci 10:2385-2399. Medline

Prolo LM, Vogel H, Reimer RJ (2009) The lysosomal sialic acid transporter sialin is required for normal CNS myelination. J Neurosci 29:1535515365. CrossRef Medline

Reimer RJ, Edwards RH (2004) Organic anion transport is the primary function of the SLC17/type I phosphate transporter family. Pflugers Arch 447:629-635. CrossRef Medline

Tritsch NX, Ding JB, Sabatini BL (2012) Dopaminergic neurons inhibit striatal output through non-canonical release of GABA. Nature 490:262-266. CrossRef Medline

Wojcik SM, Katsurabayashi S, Guillemin I, Friauf E, Rosenmund C, Brose N, Rhee JS (2006) A shared vesicular carrier allows synaptic corelease of GABA and glycine. Neuron 50:575-587. CrossRef Medline

Yuzaki M, Forrest D, Curran T, Connor JA (1996) Selective activation of calcium permeability by aspartate in Purkinje cells. Science 273:11121114. CrossRef Medline 